Interim Report

\title{
A Visual Aesthetic Prediction Method for Use in Benefit-Cost Analysis
}

Excerpt from NUREG/CR-0989, PNL-2952

Vol. II

R. C. Adams

J. W. Currie

August 1980

Prepared for

the U.S. Nuclear Regulatory Commission

Pacific Northwest Laboratory

Operated for the U.S. Department of Energy

by Battelle Memorial Institute 
NOTICE

This report was prepared as an account of work sponsored by the United States Government. Neither the United States nor the United States Nuclear Regulatory Commission, nor any of their employees, nor any of their contractors. subcontractors, or their employees, makes any warranty, express or implied, or assumes any legal liability or responsibility for the accuracy, completeness or usefulness of any information, apparatus, product or process disclosed, or represents that its use would not infringe privately owned rights.

\author{
PACIFIC NORTHWEST LABORATORY \\ operated by \\ BATTELLE \\ for the \\ UNITED STATES DEPARTMENT OF ENERCY \\ Under Contract DE-AC06-76RLO 1830
}




\title{
33679000532988
}

Interim Report

\section{A VISUAL AESTHETIC PREDICTION METHOD \\ FOR USE IN BENEFIT-COST ANALYSIS \\ Excerpt from NUREG/CR-0989, PNL-2952 Vol. II}

\author{
R. C. Adams \\ J. W. Currie
}

August 1980

Prepared for

the U.S. Nuclear Regulatory Commission

under a Related Services Agreement

with the U.S. Department of Energy

Contract DE-ACO6-76RLO 1830

Pacific Northwest Laboratory

Richland, Washington 99352 

This report discusses the development of a method to predict landscape visua? aesthetic changes caused by the siting of nuclear power plants. The methodology uses public perceptions as a measure of visual aesthetics. Individuals scored landscape photographs on a 0 to 50 visual aesthetic scale. The visual aesthetic scores were explained statistically by landscape characteristics, percent of the scene in clear, still water, and characteristics of the individua?s scoring the photographs.

Three visual aesthetic relationships were empirically estimated. The first is the relationship anong group mean visual aesthetic scores and landscape characteristics. The second is the relationship anong individual visual desthetic scores, landscape characteristics, and the characteristics of the individuals who ranked the landscapes. These relationships were estimated using data from two regions in the U.S. and a diverse set of landscape photographs. The third relationship is among group mean visual aesthetic scores for landscapes with a visible nuclear power plant, landscape characteristics, ant mean individual characteristics of the groups who scored the 1 andscapes. This relationship was estimated using data from six regions in the U.S. and landscapes showing nuclear plants with a closed cycle cooling system.

The statistical results are highly significant. Prediction validity test results indicate that the estimated relationships can predict visual aesthetic scores for groups of individuals outside the samples used to estimate the visual aesthetic relationships.

This prediction method is not intended to determine sociai welfare impact. The social welfare impact of visible change is a measure of how consumers value changes in visual aesthetics relative to all other goods and services. The prediction methodology only provides an estimate of the impact of visible change on the perceived aesthetics associated with that landscape relative to other 1 andscapes. It does not provide a measure relative to all other goods and services consumed. 


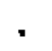

- 
CONTENTS

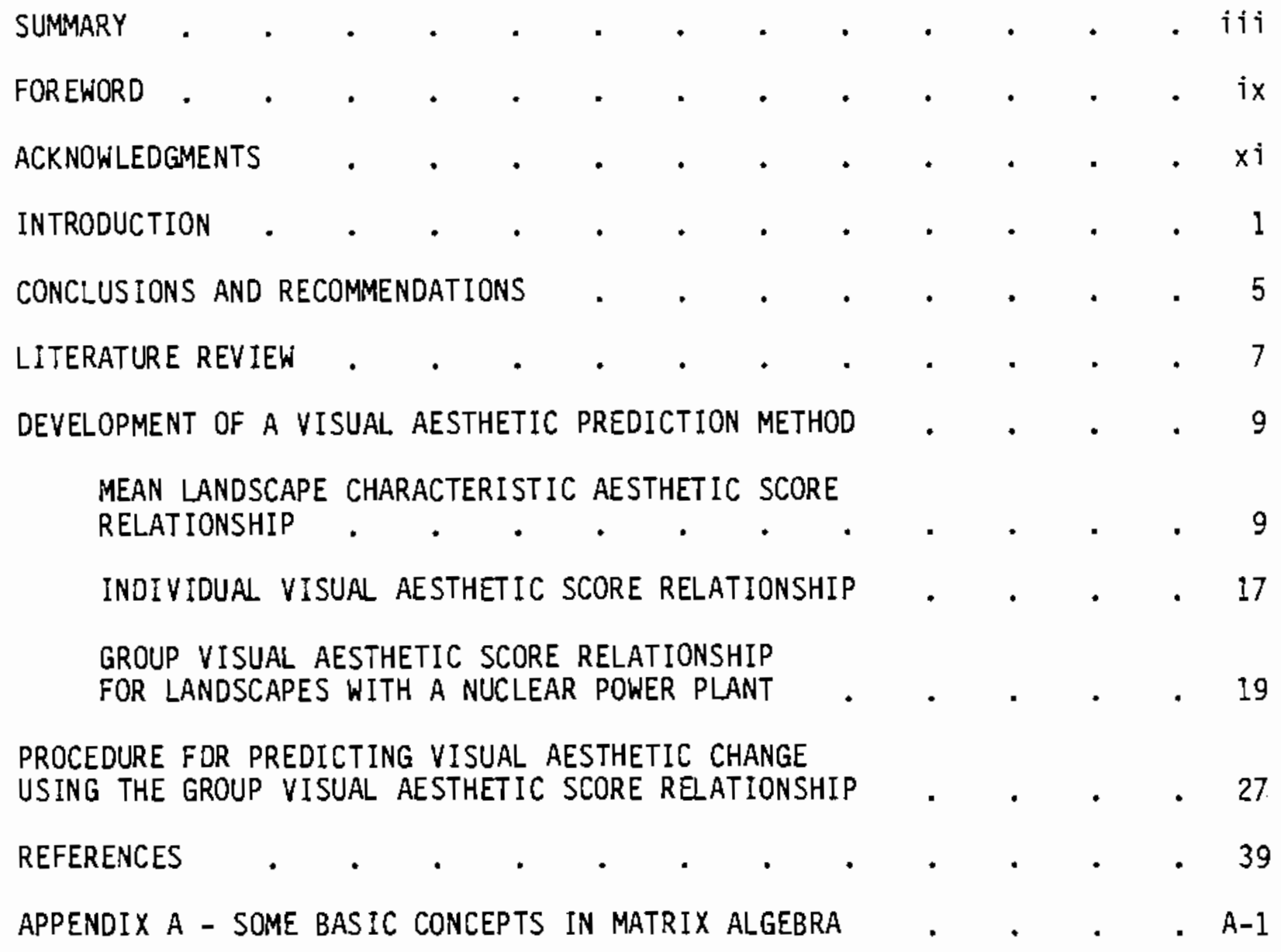




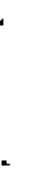




\section{FIGURES}

1 Development of the Mean Landscape Characteristic

Aesthetic Score Relationship.

2 Four Basic Steps for Calculating MLCAS . . . . . . 28

3 Application Photograph Example . . . . . . . 29

\section{TABLES}

1 Variables Determining a Landscape's Visual Aes thetics

2 Principal Component Analysis Results . . . . . . 13

3 Visual Aesthetic Variables Represented by Each Factor. . . . . . . . . . . 14

4 Mean Landscape Characteristic Aesthetic Score Relationship . . . . . . . . . . 16

5 Individual Visual Aesthetic Relationship Empirical Results . . . . . . . . . . 19

6 Group Visual Aesthetic Score Relationship--Results for Regions with Proposed or Existing Nuclear Plant . . . 24

7 Group Visual Aesthetic Score Relationship--Results for Regions with No Proposed or Existing Nuclear PTant

8 Prediction Validity Test Results: Group Visual Aesthetic Score Relationship for Nuclear Plant Lands capes

9 Variable Scores from Application Photograph . . . . . . 31

10 Vector (G) of Variable Scores from Application Photograph

11 Mean Scores and Standard Deviations . . . . . . 33

12 Standardized Variabie Scores . . . . . . . . 34

13 Factor Score Coefficients . . . . . . . . 36

14 Factor Scores . . . . . . . . . . . . 37 

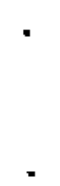


\section{FOREWORD}

This report results from a Nuclear Regulatory Comission sponsored project to determine the socioeconomic consequences from people viewing alternative closed cycle cooling systems on nuclear power plant landscapes. This was accomplished by measuring individual perceptions of visual aesthetic differences among alternative cooling systems and relating the perceived differences to individual willingness to pay and be compensated for the differences.

The contents of this report are contained within the following two-volume final report.

Currie, J. W. 1979. The Visual Impact of Alternative Closed Cycle Cooling Systems, Executive Summary. NUREG/CR-0989, PNL-2952, Pacific Northwest Laboratory, Richland, Washington.

Adams, R. C. et al. 1979. The Visual Impact of Alternative Closed Cycle Cooling Systems, Ma in Report. NUREG/CR-0989, PNL-2952, Pac if ic Northwest Laboratory, Richland, Washington.

J. W. Currie

Project Manager 


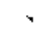

. 


\section{ACKNOWLEDGMENTS}

The authors extend appreciation to the following individuals for their technical review and valuable suggestions during the course of this research: Dr. Alan Randall of the University of Kentucky; and Michael Kaltman, Donald Cleary, David Barna, Dr. Clark Prichard, Or. Lee Abramson, and Neil Thompson of the U.S. Nuclear Regulatory Commission. 


\section{INTRODUCTION}

The research reported here was one part of a project at the Pacific Northwest Laboratory to evaluate and explain the regional social impact of visible change due to alternative closed cycle cooling systems on nuclear power plant 1 andscapes. The primary objective of the project was to develop a statistical tool that $c$ an be used with secondary data to predict the visual aesthetic impact (i.e., social welfare impact) of alternative closed cycle cooling systems. Visual aesthetic impact is defined as:

- the willingness to pay (WTP) to avoid or acquire a visual change on a landscape, or

- the willingness to accept compensation (WTA) to tolerate or forego a visual change on a landscape.

It was hypothesized that visual aesthetic impact on an individual could be explained by certain variables. These include:

- socioeconomic variables (e.g., fanily income)

- visible exposure to the tower and piant

- attitudinal variables (e.g., attitudes toward nuclear power)

- landscape visual aesthetic change (i.e., a measure of the change in landscape visual aesthetics due to a visible change in the 1 andscape).

This fourth variable is the most difficult to measure and perhaps most necessary to explain the visual aesthetic impact.

Therefore, to meet the primary objective of the project, it was necessary to develop a method for predicting visual aesthetic change that could be used to explain visual aesthetic impact from introducing alternative closed cycle cooling systems. This report describes the development for predicting a method of visual aesthetic change. This report does not deal with the relationship between visual aesthetic change and visual aesthetic impact. 
The main body of this report is divided into three sections. First, the existing literature on this topic is reviewed. Second, the development and empirical testing of three associated visual aesthetic relationships are described:

- the relationship among a group's mean landscape visual aesthetic scores and characteristics of the landscapes

- the relationship among individuals' iandscape visual aesthetic scores, characteristics of the landscapes, and the individuals

- the relationship among groups' mean landscape visual aesthetic scores for nuclear power plant landscapes, characteristics of the 1 andscapes, and the mean individual group characteristics.

The final section describes how the empirically estimated relationships can be used to predict landscape visual aesthetic change.

Two points reiated to the development of a landscape aesthetics prediction methodology should be kept in mind while reviewing this report. First, the report describes the development of an aesthetic prediction methodology as opposed to a visual structure preference prediction methodology. That is, the methodology developed $c$ an be used to predict visual aesthetic response to a landscape, including response to 1) the structural characteristics of the 1 andscape and 2) the perceived implications of the landscape. For example, visual aesthetic response to a landscape with a nuclear power plant would reflect the response to the architectural characteristics of the nuclear power plant and cooling system (if visible) and how these physical characteristics combine with the physical characteristics of the natural surrounding enyironment. In addition, to many individuals the beauty of the landscape would also be affected by the function of the structure in the landscape. Thus, the visual aesthetic response would aiso contain a component that reflected perceived health risks, or perceived employment gains, or both. Use of the visual aesthetic prediction methodology described in this report will result in a prediction containing both types of responses as described above. Also, this methodology differentiates the relative effect of both response types. 
Second, visual aesthetic change is not a relative sociai value measure. That is, visual aesthetic change does not measure visual aesthetic impact which is how a change in visual quality is valued relative to other goods and services consumed by an individual. Visual aesthetic change is a measure of relative value only among 1 andscape scenes.

Resources are scarce; thus, any decision to consume more of one particuiar kind of good (e.g., visual quality) implies that less of another good must be consumed. Thus, the visual aesthetic impact (WTP, WTA) of altering visual quality should take into consideration the relative value of altered visual quality as compared to the change in other goods and services consumed. The method discussed in this report can be used to measure visual aesthetic change relative only to the range of landscape visual quality. Thus, it would not be appropriate to use this method for directly determining the visual aesthetic impact of introducing alternative closed cycle cooling systems on a 1 andscape. 
, . 


\section{CONCLUSIONS AND RECOMMENDATIONS.}

Several conclusions were derived from this work. First, respondents were able to state their visual aesthetic preferences by assigning numbers to photographs from a 0 to 50 visual aesthetic scale. Most individuals felt the application of this technique resulted in an accurate statement of the ir landscape $v$ isual aesthetic preferences. Thus, the visual aesthetic scoring method provided an easy and accurate procedure for determining individual landscape visual aesthetics.

Second, the empirical results presented in this report show that visual aesthetic scores can be statistically explained by landscape characteristics and the characteristics of the individuals who scored the landscapes. The most important landscape characteristics include variables related to the amount of water, the number of manmade alterations, and the type of terrain in the landscape. For landscapes with minimal manmade alterations, the important individual characteristics include education, sex, and regional background. For nuclear power plant landscapes, the important individual characteristics include education, sex, nuclear attitudes, and pollution control attitudes.

Third, several individual characteristics were not important in expiaining visual aesthetic scores for nuclear power plant landscapes. These include age, current regional location, and extent of time spent in an urban versus a rural environment.

Fourth, the empirical results support the hypothesis that, when scoring the landscape photographs, individuals basically considered two factors: 1) the structural characteristics of the landscape, and 2) the perceived implication of the landscape. Both landscape structure characteristics and individual attitudes toward nuclear power were statistically important variables in explaining visua? aesthetic scores.

Fifth, the empirical relationships discussed in this report cannot be applied to all landscapes. The empirical results indicate that the form of the equations depends upon the type of 1 andscape. Two factors indicate this. First, equation form will vary among landscape type because different land. scape types will evoke different "perceived implications." Second, there was 
evidence that the relationship among some individual socioeconomic characteristics and visual aesthetic scores varied with the type of landscape.

Sixth, prediction validity test results indicate that the group visual aesthetic score relationship can be used to predict visual aesthetic scores for landscapes with a nuclear power plant.

Seventh, this work led to the testable hypothes is that visual aesthetic change (the difference between two visual aesthetic scores) due to the introduction of alternative cooling towers is significantly related to the visual aesthetic impact (WTP, WTA) of introducing the alternative systems. It was recommended that this hypothes is be tested by using a bidding game methodology to measure the visual aesthetic impact of alternative cooling systems. Statistical tests could then be undertaken to determine the nature of the relationship between visual aesthetic impact and visual aesthetic change.

This work on landscape yisual aesthetic preferences $c$ an be related to the assessment of a variety of other preferences. Empirical work could be carried out to deveiop the structural relationships among aesthetic preferences for other iandscape types (e.g., bridge landscapes, urban landscapes) and landscape and individual characteristics. Work of this type could also be extended to nonvisual preferences including noises, odors, tastes, or almost any element to which individuals react either negatively or positively. 


\section{LITERATURE REVIEW}

Previous attempts to develop a landscape visual aesthetic prediction methodology can be divided into two broad categories: those which have relied on the subjective rankings of "experts" to judge visual aesthetics; (1) and those which have relied on the "public" to judge visual aesthetics. (2-7) The use of expert judgment imp ?ies that either 1) expert judgment is superior to public judgment or 2) expert judgment is a reliable and inexpensive substitute for public judgment. Social benefit-cost analysis rejects the first reason on the grounds that public values should form the appropriate basis for decision making. The second reason is rejected because it is a hypothes is that cannot be tested until corresponding expert and public judgments of visual aesthetics are available. Thus, the a priori use of expert judgments to assess visual aesthetics appears to be a weak foundation for the development of a landscape $v$ isual aesthetic prediction methodology.

Numerous methods have been based on public judgment of visual aesthetics. Attempts to statistically explain these judgments have involved regressing landscape characteristics on a landscape's visual aesthetic score measured on some arbitrary scale.

Several common weaknesses were found in these methods. The weaknesses inc lude:

- no analysis of the relationship between individual characteristics and the visual aesthetic scores

- the absence of a statistical validity test of the method's predictive ability

- the use of subjectively measured scale variables to quantify scenic characteristics, stemining from the researchers' use of value judgment, which reduces the objectivity of the method

- the use of a limited number of scenic characteristics to explain landscape visual aesthetics, restricting the explanatory and predictive power of the method. 
DEVELOPMENT OF A VISUAL AESTHETIC PREDICTION METHOD

The approach used to develop a visual aesthetic prediction method is based on the economic theory of consumption. Consumption of landscape visual aesthetics can be theoretically related to landscape characteristics by using Lancaster's hypothesis that the utility associated with an economic good is derived from the characteristics of the good. (8)

The development and empirical testing of three associated visual aesthetic relationships are documented in this section:

- the relationship among a group's mean landscape visual aesthetic scores and characteristics of the iandscapes

- the relationship among individuals' landscape visual aesthetic scores, landscape characteristics, and individual characteristics

- the reiationship among groups' mean landscape visual aesthetic scores for nuclear power plant landscapes, landscape characteristics, and group characteristics.

\section{MEAN LANDSCAPE CHARACTERISTIC AESTHETIC SCORE RELATIONSHIP}

Figure 1 illustrates the eight steps involved in developing and est imating the mean landscape characteristic aesthetic score (MLCAS) relationship. The first step was to specify 29 landscape characteristic variables that detemine visual aesthetics. The second step was to measure these 29 variables on 40 color photographs. A $29 \times 40$ data matrix resulted from the second step. The third step involved the application of principal component analysis to the $29 \times 40$ data matrix. The fourth step was to derive factor scores from the principal components derived in Step 3 to represent each of the 40 landscapes. Fifth, landscape visual aesthetic scores for the 40 photographs were obtained from a sample of residents in or near Red Wing, Minnesota and Clay, California. Twenty people in the Red wing area and 25 respondents in the Clay area scored 40 photographs on a visual aesthetic scale from 0 to 50 . This led to the sixth step, calculating the MLCAS for each landscape. The seventh step involved the use of regression analysis to determine the empirical relationship 


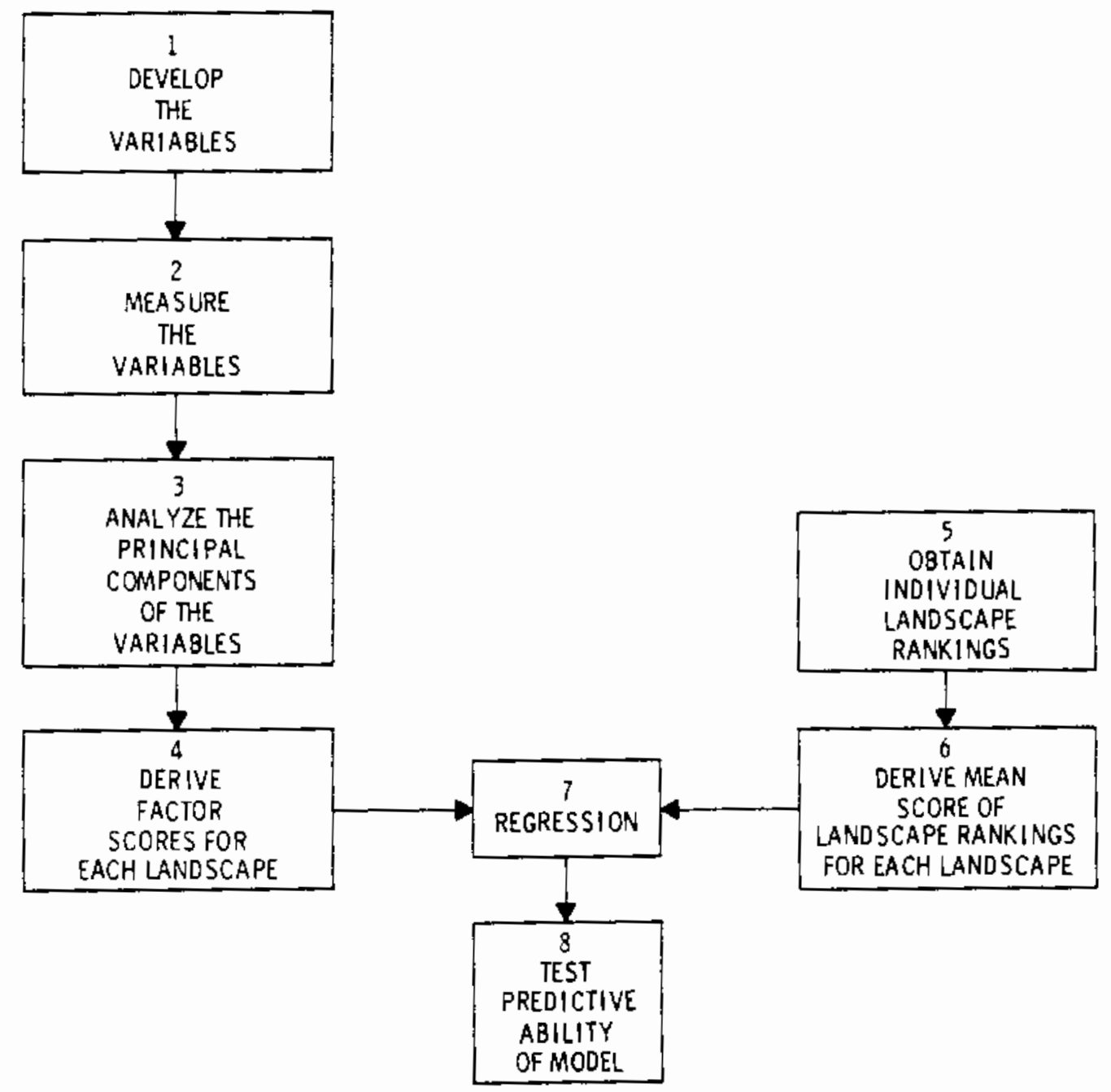

FIGURE 1. Development of the Mean Landscape Characteristic Aesthetic Score Relationship

between the factor scores and the mean aesthetic scores. The final step was to investigate the predictive ability of the relationship. These steps will be discussed in detail.

Three visual aesthetic criteria, obtained from the relevant literature, (1-7) were used in deriving the landscape characteristic variables determining visua] aesthetics:

- more complex visual patterns are usually preferred to simple ones

- the presence of water usually improves the perceived attractiveness of a landscape 
- a natural landscape is usually preferred to a manmade landscape.

Using these criteria, 29 objectively measured landscape characteristic variables were chosen. They are listed in Table 1.

The second step was to measure these variables on a set of 40 landscape photographs. A variety of landscape types was represented in the 40 photographs. Al1 variables determined in 5tep 1 were measured on the 40 photographs with the aid of a planimeter and protractor.

The third step was the application of principal component analysis to the $29 \times 40$ data matrix generated in the second step. Principal component analysis was used in developing this method for two reasons. First, it reduces the size of the data matrix to manageable proportions. If the data matrix were not reduced, the application of regression analysis would result in a severe loss of degrees of freedom. Second, the use of factor scores in a regression equation bypasses any multicollinearity problem that may have existed if regression analysis had been applied to the original variables.

The results of applying principal component analysis to the data matrix are shown in Table 2. Factor scores were derived for the first 10 factors. The variables represented by these factors are shown in Table 3.

The fourth step was to derive factor scores for each landscape. The factor score matrix was derived by multiplying the $10 \times 29$ matrix of factor score coefficients (i.e., the matrix of eigenvectors derived from the variable correlation matrix) by the $29 \times 40$ matrix of standardized variable scores, the standardized form of the data matrix derived in Step 2. The standardized form of the data matrix was obtained from the original data matrix by subtracting from each matrix element the corresponding mean of the variable and dividing the difference by the corresponding standard deviation of the variable.

The fifth step involved obtaining visual aesthetic scores from a sample of 20 individuals in or near Red Wing. Minnesota, and 25 individuais in or near Clay, California. Each cooperating subject ranked the visual aesthetics of 20 color landscape photographs. Combining the Clay and Red Wing samples, half of the 40 photographs were scored by 20 people (11 from California, 9 from Minnesota); the other half were scored by 25 people (14 from California, 11 from Minnesota). 
TABLE 1. Variables Determining a Landscape's Visual Aesthetics

\begin{tabular}{|c|c|}
\hline $\begin{array}{l}\text { Variable } \\
\text { Number }\end{array}$ & Variable \\
\hline 1 & Percent of scene in clear, still water \\
\hline 2 & Percent of scene in clear, flowing water \\
\hline 3 & Slope of the steepest part of the river \\
\hline 4 & Slope of the flattest part of the river \\
\hline 5 & Percent of scene in white-water rapids \\
\hline 6 & Number of peaks in background \\
\hline 7 & Number of peaks in foreground \\
\hline 8 & Percent of scene in open fields (no trees or crops) \\
\hline 9 & Slope of steepest bank to water \\
\hline 10 & Slope of flattest bank to water \\
\hline 11 & Percent of scene in cropland \\
\hline 12 & $\begin{array}{l}\text { Percent of scene in trees in summer foliage (including } \\
\text { evergreens if summer scene; i.e., if the scene appears to have } \\
\text { warm temperatures, then include evergreens) }\end{array}$ \\
\hline 13 & Percent of scene in trees (total) \\
\hline 14 & Number of distinct tree types in the scene \\
\hline 15 & Percent of scene in residential buildings \\
\hline 16 & Percent of scene in power transmission facilities \\
\hline 17 & $\begin{array}{l}\text { Percent of scene in manmade objects of wood, stone and brick } \\
\text { (not garbage or residences) }\end{array}$ \\
\hline 18 & $\begin{array}{l}\text { Percent of scene in other manmade objects (not garbage or } \\
\text { residences) }\end{array}$ \\
\hline 19 & Percent of scene covered by industrial parks and plant \\
\hline 20 & Percent of scene in manmade objects (not roads) \\
\hline 21 & Percent of scene in paved roads \\
\hline 22 & Percent of scene in gravel roads \\
\hline 23 & Percent of scene in garbage and debris from man \\
\hline 24 & Percent of scene altered by human activity \\
\hline 25 & $\begin{array}{l}\text { Number of components in the scene (components include types of } \\
\text { structures and plant life, topographical and geological } \\
\text { features) }\end{array}$ \\
\hline 26 & $\begin{array}{l}\text { Number of distinct colors in the scene (distinct refers even } \\
\text { to different shades of the same color) }\end{array}$ \\
\hline 27 & Slope of steepest part of background \\
\hline 28 & Slope of steepest part of foreground \\
\hline 29 & Percent of scene in recreational areas \\
\hline
\end{tabular}


TABLE 2. Principal Component Analys is Results

\begin{tabular}{|c|c|c|c|}
\hline Factor & Eigenvalue & $\begin{array}{l}\text { Marginal } \% \\
\text { of Variance } \\
\text { Explained } \\
\end{array}$ & $\begin{array}{l}\text { Cumulative } \% \\
\text { of Variance } \\
\text { Explained }\end{array}$ \\
\hline 1 & 5.50342 & 19.0 & 19.0 \\
\hline 2 & 3.86831 & 13.3 & 32.3 \\
\hline 3 & 2.47303 & 8.5 & 40.8 \\
\hline 4 & 2.01565 & 7.0 & 47.8 \\
\hline 5 & 1.89304 & 6.5 & 54.3 \\
\hline 6 & 1.74296 & 6.0 & 60.3 \\
\hline 7 & 1.60779 & 5.5 & 65.9 \\
\hline 8 & 1.49093 & 5.1 & 71.0 \\
\hline 9 & 1.26343 & 4.4 & 75.4 \\
\hline 10 & 1.20604 & 4.2 & 79.5 \\
\hline 11 & 0.94351 & 3.3 & 82.8 \\
\hline 12 & 0.91565 & 3.2 & 85.9 \\
\hline 13 & 0.80152 & 2.8 & 88.7 \\
\hline 14 & 0.63267 & 2.2 & 90.9 \\
\hline 15 & 0.45913 & 1.6 & 92.5 \\
\hline 16 & 0.40984 & 1.4 & 93.9 \\
\hline 17 & 0.34168 & 1.2 & 95.1 \\
\hline 18 & 0.29268 & 1.0 & 96.1 \\
\hline 19 & 0.26561 & 0.9 & 97.0 \\
\hline 20 & 0.22827 & 0.8 & 87.8 \\
\hline 21 & 0.19630 & 0.7 & 98.5 \\
\hline 22 & 0.14244 & 0.5 & 98.9 \\
\hline 23 & 0.12090 & 0.4 & 99.4 \\
\hline 24 & 0.06715 & 0.2 & 99.6 \\
\hline 25 & 0.05600 & 0.2 & 99.8 \\
\hline 26 & 0.03832 & 0.1 & 99.9 \\
\hline 27 & 0.01397 & 0.0 & 100.0 \\
\hline 28 & 0.00946 & 0.0 & 100.0 \\
\hline 29 & 0.00032 & 0.0 & 100.0 \\
\hline
\end{tabular}


TABLE 3. Visual Aesthetic Variables Represented by Each Factor

\begin{tabular}{|c|c|c|}
\hline Factor & Variable & Variable \\
\hline 1 & $\begin{array}{r}3 \\
4 \\
9 \\
10\end{array}$ & $\begin{array}{l}\text { Slope of the steepest part of the river } \\
\text { Slope of the flattest part of the river } \\
\text { Slope of the steepest bank to water } \\
\text { Slope of the flattest bank to water }\end{array}$ \\
\hline 2 & $\begin{array}{l}2 \\
5\end{array}$ & $\begin{array}{l}\text { Percent of scene in clear, flowing water } \\
\text { Percent of scene in white-water rapids }\end{array}$ \\
\hline 3 & $\begin{array}{l}16 \\
23 \\
24\end{array}$ & $\begin{array}{l}\text { Percent of scene in power transmission facilities } \\
\text { Percent of scene in garbage and debris from man } \\
\text { Percent of scene altered by human activity }\end{array}$ \\
\hline 4 & $\begin{array}{r}7 \\
21\end{array}$ & $\begin{array}{l}\text { Number of peaks in the foreground } \\
\text { Percent of scene in paved roads }\end{array}$ \\
\hline 5 & $\begin{array}{l}17 \\
18\end{array}$ & $\begin{array}{l}\text { Percent of scene in manmade objects of wood, stone and } \\
\text { brick (not garbage or residences) } \\
\text { Percent of scene in other manmade objects (not garbage } \\
\text { or residences) }\end{array}$ \\
\hline 6 & $\begin{array}{l}12 \\
13 \\
14 \\
29\end{array}$ & $\begin{array}{l}\text { Percent of scene in trees in summer foliage(a) } \\
\text { Percent of scene in trees } \\
\text { Number of distinct tree types in scene } \\
\text { Percent of scene in recreational area }\end{array}$ \\
\hline 7 & $\begin{array}{r}8 \\
19 \\
20\end{array}$ & $\begin{array}{l}\text { Percent of scene in open fields (not trees or crops) } \\
\text { Percent of scene covered by industrial parks and plant } \\
\text { Percent of scene in manmade objects }\end{array}$ \\
\hline 8 & $\begin{array}{r}6 \\
11 \\
26\end{array}$ & $\begin{array}{l}\text { Number of peaks in background } \\
\text { Percent of scene in cropland } \\
\text { Number of distinct colors in scene }\end{array}$ \\
\hline 9 & 15 & Percent of scene in residential buildings \\
\hline 10 & $\begin{array}{l}22 \\
25\end{array}$ & $\begin{array}{l}\text { Percent of scene in gravel roads } \\
\text { Number of components in scenela) }\end{array}$ \\
\hline
\end{tabular}

(a) These variables are explained further in Tabie 1. 
The photographs were scored on a scale between 0 and 50 . The respondents were told four things: 1) 50 represents the most beautiful scene they had ever seen; 2) 0 represents the ugliest scene they had ever seen; 3) they did not have to assign any picture a score of 0 or 50 ; and, 4) more than one picture could receive the same score.

In Step 6, the group mean score for each landscape was calculated to represent a measure of the landscape's visual aesthetics. Using the mean score does not imply all individuals have equal taste. Variations in individual taste could lead to wide variations about the mean response.

The seventh step was to empirically estimate the relationship between the factor scores and the mean score (MLCAS) of a given landscape. This estimation invoived the use of regression analysis.

Corresponding to the theoretical relationship between the consumption of visual aesthetics and characteristics of the scene, the following relationship was hypothesized:

$$
\bar{Y}_{i}=\frac{\sum_{i} A_{i}}{N}=B_{1}+\beta_{2} f_{i, 1}+\ldots+B_{11} f_{i, 10}+e_{i}
$$

where

$$
\begin{aligned}
\bar{Y}_{i} & =\frac{\sum_{j} A_{i}=\text { the mean score of all individual landscape characteristic }}{N} \text { aesthet } i c \text { scores }\left(A_{i}\right) \text { for scene } i \\
f_{i, k} & =\text { the factor score for scene } i \text { on factor } k \\
e_{i} & =\text { the disturbance term for scene } i .
\end{aligned}
$$

Equation (1) was estimated with the combined data from Minnesota and California. The results are shown in Table 4. The factor coefficient signs were the same as the hypothesized signs. Factor 4 was the oniy factor insignificant at the $10 \%$ level. This result is not overly surprising due to the relatively small variation in Factor 4 variables over the 40 photographs. 
TABLE 4. Mean Landscape Characteristic Aesthetic Score Relationship

\begin{tabular}{|c|c|c|}
\hline Factor & B coefficient & $t$ to remove \\
\hline 1 & 4.386 & 6.79 \\
\hline 2 & 3.186 & 4.95 \\
\hline 3 & -6.354 & 9.82 \\
\hline 4 & 0.570 & 0.88 \\
\hline 5 & -1.270 & 1.92 \\
\hline 6 & 5.138 & 7.93 \\
\hline 7 & -4.447 & 6.82 \\
\hline 8 & 2.539 & 3.40 \\
\hline 9 & -2.531 & 3.92 \\
\hline 10 & 1.247 & 1.88 \\
\hline Constant & 27.407 & 42.26 \\
\hline $\begin{array}{l}R^{2}=0.8262 \\
\text { Adjusted } R^{2}=0.8011 \\
\text { Overall } F=32.81\end{array}$ & & \\
\hline
\end{tabular}

A test for the existence of any regional differential in visual aesthetics was also performed. This test invoived estimating Equation (1) separately using only data from Minnesota and then estimating Equation (1) using only California data. A Chow test was used to test the null hypothesis of no significant difference in regression coefficients between the two regions. (9) Resuits confirmed the null hypothesis $\left(F_{58}^{11}=0.19\right)$. (a)

The final step in developing and estimating the MLCAS relationship was to test its predictive ability. A statistical test was administered to determine if the structure of the model was generalizable to groups and landscapes outside the original sample set. $(10, \mathrm{pp} .556-557)$

(a) Bias could be present in this experiment because probability sampling was not used. 
First, factor scores were derived using the original principal component analysis results for 10 photographs outside the original sample set. Next, these factor scores were used with Equation (1) to predict 10 MLCASs ( $\hat{\bar{Y}}_{m}$, $\mathrm{m}=1, \ldots, 10)$.

Twenty-eight subjects residing in eastern washington scored the 10 photographs on the 0 to 50 visual aesthetic scale. The MLCASs $\left(\bar{Y}_{m}\right)$ over the 28 subjects were subtracted from the predicted MLCASs $\left(\hat{\bar{Y}}_{m}\right)$. These differences were divided by the estimated standard deviations of the forecast errors, $\hat{\sigma}_{v}$. Under the assumption that the disturbance term, $e_{j}$, in Equation (1) is normally distributed with mean zero and variance $\hat{\sigma}_{T}^{2}$, the resulting quantity is distributed $t$ with T-K degrees of freedom. That is,

$$
t_{T-K}=\frac{\left(\hat{\bar{Y}}_{m}-\bar{Y}_{m}\right)}{\hat{\sigma}_{V}}
$$

where $T$ is the sample size and $K$ is the number of explanatory variables.

This quantity ( $t$ ) can be used to test the null hypothesis that the structure of the model derived from using the original sample set can be applied to both the original sample-set as well as to the photographs and individuals outside that original set. For each of the 10 photographs, no significant differences at the $5 \%$ level existed between the observed and predicted mean scores.

INDIVIDUAL VISUAL AESTHETIC SCORE RELATIONSHIP

The consumption of visual aesthetics may be related to the individual score as well as to the MLCAS. The same data set that was used to estimate the MLCAS relationship was used to test the significance of individual characteristics in explaining individual visual aesthetic scores.

A number of characteristics were hypothesized as being potentialiy related to visual aesthetic scores. These include age, sex, education, place of residence between the ages of 10 and 18, and whether the individual had 
lived most of his life in an urban or rural setting. It was expected that the level of exposure to a variety of visual environments, the relative value of visual aesthetic consumption, and the type of visual environment most farliliar to the individual would be important factors in explaining landscape visual aesthetics. The hypothesized socioeconomic and demographic characteristic variables were used as proxies for these factors. The empirical work discussed below is a preliminary test designed to provide information on the importance of these factors in explaining landscape visual aesthetics.

The structure of the individual visual aesthetic relationship was hypothesized to take the form

$$
\begin{aligned}
\text { VAS }_{i j} & =\beta_{1}+\beta_{2} S_{1, i}+\ldots+B_{11} S_{10, i}+\beta_{12} \text { Ed }_{j} \\
& +\beta_{13} \text { Age }_{j}+\beta_{14} \text { Sex }_{j}+\beta_{15} \text { Hist }_{j}+\beta_{16} \text { Set }_{j}
\end{aligned}
$$

where

$$
\begin{aligned}
\text { VAS }_{i j}= & \text { individual } j \text { 's visual aesthetic score for scene } j \\
S_{1, i}, \ldots, S_{10, j}= & 10 \text { factor scores for scene } i \text { derived from objective. } \\
& \text { variable scores taken from scene } i \\
E d_{j}= & \text { individual } j \text { 's education leve } 1 \\
A_{j}= & \text { individual } j \text { 's age } \\
S_{j}= & \text { individual } j \text { 's sex }(0=\text { male, } 1=\text { female }) \\
\text { Hist }_{j}= & \text { individual } j \text { 's place }(s) \text { of residence between the } \\
& \text { ages of } 10 \text { and } 18 . \text { If individual lived then in the } \\
& \text { region in which he now resides, Hist }=0 . \text { If the } \\
& \text { individua } \text { lived elsewhere between } 10 \text { and } 18, \\
& H \text { Hst }=1 . \text { (a) }
\end{aligned}
$$

(a) This scheme was sufficient to capture all variation in history because 1) no individual sampled in the Red Wing, Minnesota, region lived outside that region between the ages of 10 and 18 , and 2) only four individuals sampled lived outside the Clay, California, region; all four lived in the south-midwest region between the ages of 10 and 18 . 


$$
\begin{aligned}
\text { Set }_{j}= & \text { If individual } j \text { lived in an urban setting most of } \\
& \text { his } l \text { ife, Set }=1 . \text { If he lived in a rural area, } \\
& \text { Set }=0 .
\end{aligned}
$$

Equation (3) was estimated with pooled data from Red Wing, Minnesota and Clay, California. The results are shown in Table 5. The only variables

\begin{tabular}{|c|c|c|}
\hline Factor & $\beta$ coefficient & $t$ to remove \\
\hline 1 & 4.267 & 11.55 \\
\hline 2 & 3.199 & 7.89 \\
\hline 3 & -6.408 & 16.34 \\
\hline 4 & 0.803 & 1.99 \\
\hline 5 & -1.401 & 3.67 \\
\hline 6 & 5.277 & 13.78 \\
\hline 7 & -4.566 & 11.83 \\
\hline 8 & 2.636 & 5.94 \\
\hline 9 & -2.610 & 6.85 \\
\hline 10 & 1.081 & 2.62 \\
\hline Sex & 2.262 & 2.46 \\
\hline Age & -0.030 & 0.80 \\
\hline Ed & -0.753 & 1.97 \\
\hline Hist & 1.081 & 2.37 \\
\hline Set & 0.386 & 0.85 \\
\hline Constant & 29.174 & 10.70 \\
\hline $\begin{array}{l}R^{2}=0.5206 \\
\text { Adjusted } R^{2}=0.5125 \\
\text { Overal1 } F=63.996\end{array}$ & & \\
\hline
\end{tabular}
insignificant at the 5\% level are setting (Set) and age.

TABLE 5. Individual Visual Aesthetic Relationship

GROUP VISUAL AESTHETIC SCORE RELATIONSHIP FOR LANOSCAPES WITH A NUCLEAR POWER PLANT

The visual aesthetic impact of alternative closed cycle cooling systems was analyzed using data collected on WTP to remove or prevent and WTA to 
tolerate or forego a visible landscape change at six sites around the United States. At each of these six sites the data gathered included nuclear plant landscape visual aesthetic scores on the 0 to 50 scale described earlier.

The data were gathered at intact group meetings (e.g., unions, environmental groups, chambers of commerce). After applying several selection criteria to remove nonrepresentative data, the remaining data were aggregated to mean intact group data. The aggregated data were used to confirm the visual aesthetic impact and visual aesthetic change relationship. (11)

An across groups mean visual aesthetic score (group VAS) relationship for nuclear plant landscapes was developed so that visual aesthetic impact could be accurately predicted using the relationship between visual aesthetic impact and visual aesthetic change described above. The across groups relationship is based on predicted MLCAS, mean characteristics for each group, and mean nuclear plant landscape visual aesthetic scores.

The data set used to develop the group VAS relationship contained approximateiy 1440 visual aesthetic scores. A total of 28 picture sets were scored. The pictures were of four existing or proposed nuclear plant sites. Seven different variations existed on each group of site photographs. These variations were:

1. no tower, no plume

2. mechanical draft tower, no plume

3. natural draft tower, no plume

4. mechanical draft tower, small plume

5. natural draft tower, small plume

6. mechanical draft tower, large plume

7. natural draft tower, large plume.

A picture set contained two photographs. One showed the nuclear plant and a cooling tower option at a distance of $1 / 2$ to $11 / 2$ miles. The second showed the same nuclear plant and same cooling tower option at a distance of 5 to 7 miles. The photograph sets were ranked by 160 people. Each person scored, on average, approximately nine photograph sets. 
The structure of the group VAS relationship was hypothesized to take the following form for regions with proposed or existing nuclear plants:

$$
\begin{aligned}
\text { VAS }_{i j}= & \beta_{1}+\beta_{2} \text { MLCAS }_{i}+\beta_{3} \text { Ed }_{j}+\beta_{4} \text { Age }_{j} \\
& +\beta_{5} \text { Sex }_{j}+\beta_{6} \text { HiSt }_{j}+\beta_{7} \text { Set }_{j}+\beta_{8} \text { NPA }_{j}+\beta_{9} \text { OWTW }_{j}
\end{aligned}
$$

where

$$
\begin{aligned}
\text { VAS }_{i j}= & \text { group } j \text { 's mean visual aesthetic score for photograph set } i \\
\text { MLCAS }_{i}= & \text { the predicted MLCAS for photograph set } i \\
\text { NPA }_{j}= & \text { group } j \text { mean score on the nuclear attitude question, "The } \\
& \text { potential hazards of nuclear power plants are small compared } \\
& \text { to the consequences of doing without the electricity that } \\
& \text { they generate." The scores ranged from } 1 \text { to } 7 \text {, with } 1 \\
& \text { representing "strongly agree", } 7 \text { representing "strongly } \\
& \text { disagree", and } 4 \text { representing "neither agree nor disagree." } \\
\text { OWTW }_{j}= & \text { a dummy variable indicating whether the photograph set } \\
& \text { being rated by group } j \text { contains a cooling tower type } \\
& \text { (mechanical, natural) that exists at their local plant. The } \\
& \text { variable was set equal to } 0 \text { if the photograph set did not } \\
& \text { have the same cooling tower type or if the group resided in a } \\
& \text { region with a proposed plant. The variable was set equal to } \\
& 1 \text { if the photograph set did have the same cooling tower type. }
\end{aligned}
$$

Additional variables were added to those that appear in Equation (3) (the individual relationship) because nuclear power plants were present in all photograph sets and because the data were taken from regions with either a proposed or existing nuclear plant. Landscape visual aesthetics would be unreiated to nuclear power attitude $\left(\mathrm{NPA}_{j}\right)$ if the individuals who scored the nuclear power plant landscapes did so strictly on visual structure criteria. However, the nuclear plant landscape scores reflected another component in addition to visual structure criteria. The scores also reflected the fact that some individuals were reminded of perceived health and safety costs 
associated with nuclear power plants when looking at the landscape pictures. Other individuals were reminded of perceived growth and employment benefits associated with nuclear power plants when looking at the landscape pictures. It was hypothesized that the visual aesthetic scores would be negatively related to NPA (j.e., individuals with anti-nuclear attitudes would score the scenes lower, ceteris parabus, than pro-nuclear individuals).

OWTW was expected to be positively related, ceteris parabus, to visual aesthetic score. This expectation was based on the hypothes is that individuals would not find a tower they had seen numerous times nearly as visually offensive as a tower they were unaccustomed to seeing. Individuals residing in an area with a proposed plant were, of course, unexposed to any tower. Thus, it was appropriate to set OWTW equal to zero for these regions.

The relationship used to derive MLCAS see Equation (1) was empirically estimated using a diverse set of landscape photographs. Some of the photographs showed manmade structures; others did not. In almost all cases, the function of the structures in the photographs was not easily discernable. Thus, MLCAS basically reflects visual aesthetic response to the landscape characteristics (as defined in Table 1; these, for the most part, do not include the function of any structure in the landscape) of the photograph.

Note that the structure of Equation 4 implies that, for any given group, visual aesthetic score difference between two nuclear power plant landscapes will be determined by MLCAS. That is, if one group scores two nuclear power plant landscapes that are identical except for cooling tower type, the difference between the two scores will reflect only visual aesthetic response to the change in architectural characteristics (cooling tower designs) between the two landscapes. The other determinants of one visual aesthetic score (i.e., group characteristics) will cancel out when visual aesthetic change is determined, because they would not vary between nuclear power plant landscapes.

The structure of the group VAS relationship was hypothesized to take the following form for regions with no proposed or existing nuclear plants:

$$
\begin{aligned}
\text { VAS }_{i j}=B_{1} & +\beta_{2} \text { MLCAS }_{i}+\beta_{3} \text { Ed }_{j}+\beta_{4} \text { Age }_{j} \\
& +\beta_{5} \text { Sex }_{j}+\beta_{6} \text { Hist }_{j}+\beta_{7} \text { Set }_{j}+\beta_{8} \text { PCA }_{j}
\end{aligned}
$$


where

$$
\begin{aligned}
P C A_{j}= & \text { group } j \text { mean score on the pollution attitude question, "Unless } \\
& \text { a more stringent pollution control program is established now, } \\
& \text { we will face serious environmental deterioration in the near } \\
& \text { future." The scores ranged from } 1 \text { to } 7 \text {, with } 1 \text { representing } \\
& \text { "strongly agree", } 7 \text { representing "strongly disagree", and } 4 \\
& \text { representing "neither agree nor disagree." }
\end{aligned}
$$

Nuclear attitude (NPA) was not included in the hypothesized structure because the data used were from regions with no proposed or existing nuclear plant. Individuals in these regions typically had never seen a nuclear power plant cooling tower or plume. It was hypothesized that, due to 1) their lack of experience with nuclear plants, and 2) the presence of thermal plumes, their visual aesthetic scores would be more directly related to pollution attitudes rather than nuclear attitudes. The PCA coefficient, 8 , was expected to have a positive sign. As when using Equation (4), visual aesthetic score difference between two nuclear power plant landscapes would reflect the change in MLCAS (i.e., the response to architectural change).

Initial empirical work on Equations (4) and (5) showed Age, Set (urban or rural background) and Hist (residence between 10 and 18 years of age) to be consistently insignificant. These variables were removed from the hypothesized structure as being unrelated to visual aesthetic score. In addition, MLCAS and group characteristic interaction variabies were tested and found insignificant. Final empirical results are shown in Tables 6 and 7.

The individual visual aesthetic relationship indicated females rate landscape scenes, ceteris parabus, significantly higher than do males (see Tabie 5). VAS relationship empirical results indicated males rate nuclear power plant landscapes, ceteris parabus, significantly higher than do females. This result indicates a structural difference between the explanation of visual aesthetics for nuclear plant landscapes and other landscapes. It is hypothesized that females respond relatively more favorably to landscapes showing no manmade elements and males respond relatively more favorably to landscapes with manmade elements that symbolize growth and technological development. 
IABLE 6. Group Visual Aesthetic Score Relationship--Regions with Proposed or Existing Nuclear Plant

\begin{tabular}{|c|c|c|}
\hline Variable & B Coefficient & $t$-Test \\
\hline MLCAS & 2.775 & 7.33 \\
\hline SEX & 10.352 & 4.30 \\
\hline ED & -4.823 & 5.60 \\
\hline NPA & -1.412 & 2.42 \\
\hline OWTW & 13.601 & 6.36 \\
\hline Constant & -44.477 & 4.07 \\
\hline
\end{tabular}

Adjusted $R^{2}=0.5087$

$F=21.295$

Tests for regional variation were performed. No systematic significant differences were discovered among any of the six regions. These results support similar regional variation test results carried out on the individual visual aesthetic relationship.

The empirical results reported in Table 6 indicate the nuclear plant landscapes were scored on a relative visual aesthetic scale that differed from the scale upon which the diverse set of landscapes were scored to estimate the MLCAS and individual visual aesthetic relationships. The 2.775 MCAS coefficient in Table 6 indicates that a I-point increase on the MLCAS relationship

TABLE 7. Group Visual Aesthetic Score Relationship--Regions With No Proposed or Existing Nuclear Plant

\begin{tabular}{|c|c|c|}
\hline Variable & B Coefficient & t-Test \\
\hline MLCAS & 1.445 & 5.98 \\
\hline SEX & 2.194 & 0.93 \\
\hline ED & -0.872 & 1.39 \\
\hline PCA & 3.444 & 6.57 \\
\hline Constant & -28.552 & 3.99 \\
\hline
\end{tabular}

Adjusted $R^{2}=0.4053$

$F=17.184$ 
corresponds, ceter is parabus, to a 2.775-point increase on the VAS relationship for regions with a proposed or existing nuclear plant. Similarly, Table 7 indicates that a 1-point increase on the MLCAS relationship corresponds, ceteris parabus, to a 1.445-point increase on the VAS relationship for regions with neither a proposed nor existing nuclear $p l$ ant. It is hypothesized that this occurred because the nuclear plant landscapes were very similar when compared to the diverse landscapes used to estimate the individual visual aesthetic relationship and, as a result, a different relative scale was used to score the nuclear plant landscapes as compared to the diverse landscapes.

Prediction validity tests were carried out for the equation in Table 6. The purpose of these tests was to determine whether the structural equations derived from the intact sample could be used to predict nuclear plant landscapes visual aesthetic scores for groups outside the original sample set.

In addition to the intact sample, two random household samples were gathered at two of the six sites. One site had an existing nuclear plant. A nuclear plant was proposed for the other site. The random sample results were used to test whether structural equations derived from the intact sample could be used to predict random sample responses. The random sample results were subjected to the same selection criteria as the intact sample had been. The remaining data were used to carry out the validity tests.

All validity tests carried out were similar to the one described earlier in this report (see page 17). Mean characteristics from the random sample were used with the equation from Table 6 to derive a predicted VAS $(\hat{\bar{Y}})$. The difference between $\hat{\bar{Y}}$ and the actual random sample score $(\bar{Y})$ was divided by the standard deviation of the forecast error to test the null hypothes is of no structural difference between the intact and random visual aesthetic score responses.

The random sample results from those individuals who scored pictures of the proposed Perkins, North Carolina plant were used. Data from approximately 22 individuals who lived in the Perkins site area were used to calculate $\bar{Y}$. A portion of the validity test results are presented in Table 8 . 
TABLE 8. Prediction Validity Test Results: Group Visual Aesthetic Score Relationship for Nuclear Plant Landscapes

\begin{tabular}{lc}
\multicolumn{1}{c}{ Picture (of Perkins, N.C. } & $\begin{array}{c}\text { t-Test of } \\
\text { Site) }\end{array}$ \\
\cline { 1 - 3 } No tower, no plume & 0.025 \\
Mechanical draft tower, no plume & 0.14 \\
Naturai draft tower, no plume & 1.12 \\
Mechanicai draft tower, iarge plume & 0.58 \\
Natural draft tower, large plume & 1.10
\end{tabular}

The results presented in Table 8 are typical of all the tests. All the $t$-test scores are less than the critical $t$ value $\left(t_{.05}^{\star}=1.96\right)$. This indicates that the VAS relationship can be used to predict nuclear power plant landscape visual aesthetic scores for at least one group outside those used to estimate the equations in Tables 6 and 7. This is a highly significant result because predicting VAS differences is required for predicting visual aesthetic impact at proposed nuclear plant site locations. 


\section{PROCEDURE FOR PREDICTING VISUAL AESTHETIC CHANGE USING}

\section{THE GROUP VISUAL AESTHETIC SCORE RELATIONSHIP}

This section presents a step-by-step description of how to calculate mean landscape characteristic aesthetic score (MLCAS). The difference between the group visual aesthetic scores for two landscapes is defined as a visual aesthetic change. This information will input directly into the procedure for predicting the visual aesthetic impact of alternative closed cycle cooling sys tems.

Figure 2 shows the four basic steps in determining the MLCAS for a landscape. Step 1 requires the analyst to make actual measurements on the relevant photograph. In Steps 2 through 4 , the analyst uses predetermined coefficients and formulae to transform the measures derived via Step 1 to a predicted visual aesthetic score.

Step 1 is to determine the variable scores, $g_{1}$ through $g_{29}$, for each photograph. Consider the picture shown in Figure 3 . The 29 variables specified in Table 1 (p.12) can be measured with the aid of a protractor and a planimeter. The results are shown in Table 9.

The variable scores shown in Table 9 comprise a vector (referred to as $G$ ) of variable scores, shown in Table 10.

Step 2 is the derivation of standardized variable scores (S) from the vector of variable scores (G). $S$ is derived by subtracting the mean score of the variable $\left(\bar{g}_{j}\right)$ from each variable score $\left(g_{j}\right)$ and dividing the difference by the standard deviation of the variable $\left(\sigma_{j}\right)$. In mathematical notation,

$$
s_{j}=\frac{g_{j}-\bar{g}_{j}}{\sigma_{j}}
$$

where

$j=$ subscript denoting the $j^{\text {th }}$ variable $(j=1$ to 29$)$

$s_{j}=$ the standardized variable score for variable $j$

$g_{j}=$ the variable score for variable $j$

$\bar{g}_{j}=$ the mean score of variable $j$

$\sigma_{j}=$ the standard deviation of variable $j$. 


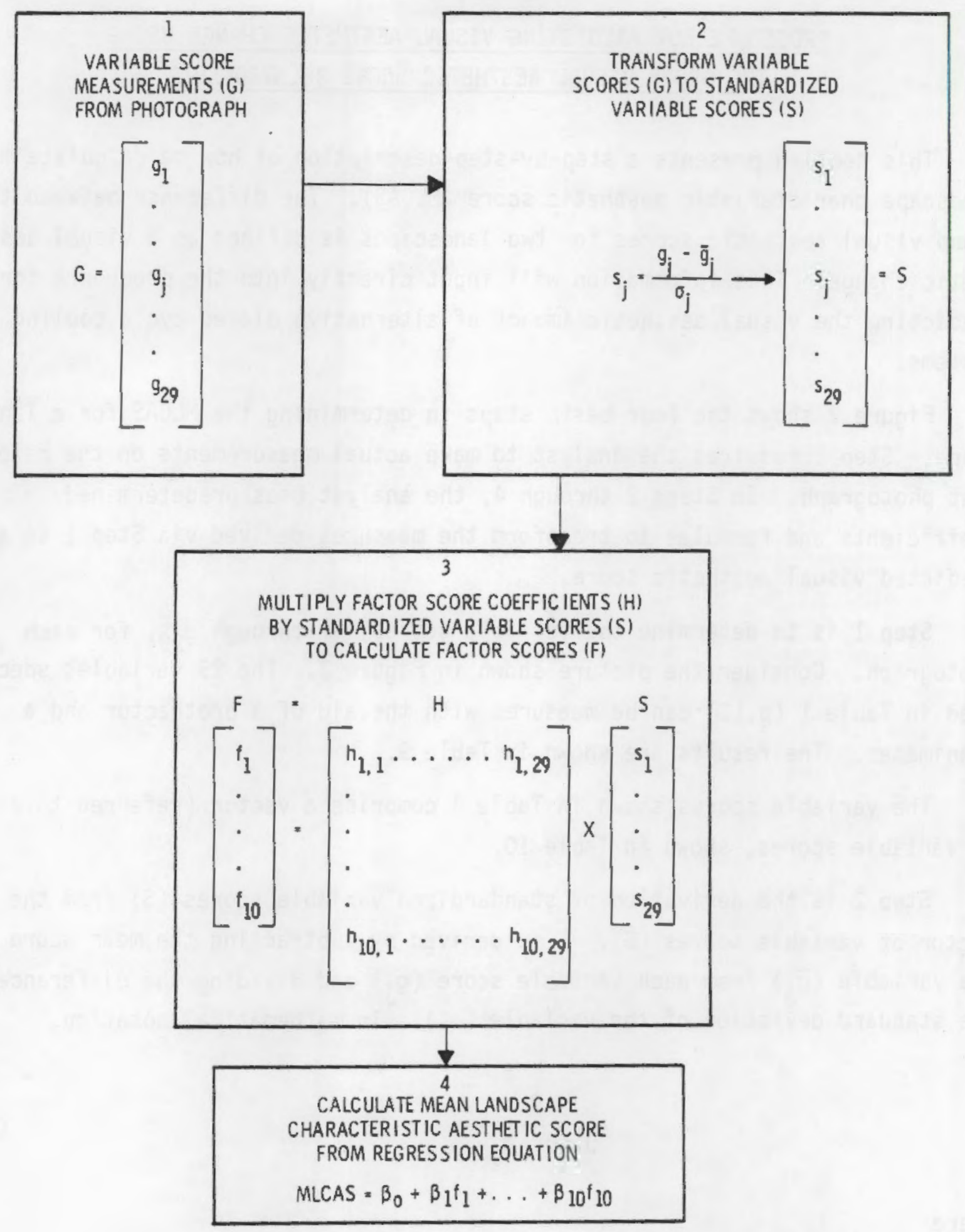

FIGURE 2. Four Basic Steps for Calculating MLCAS 


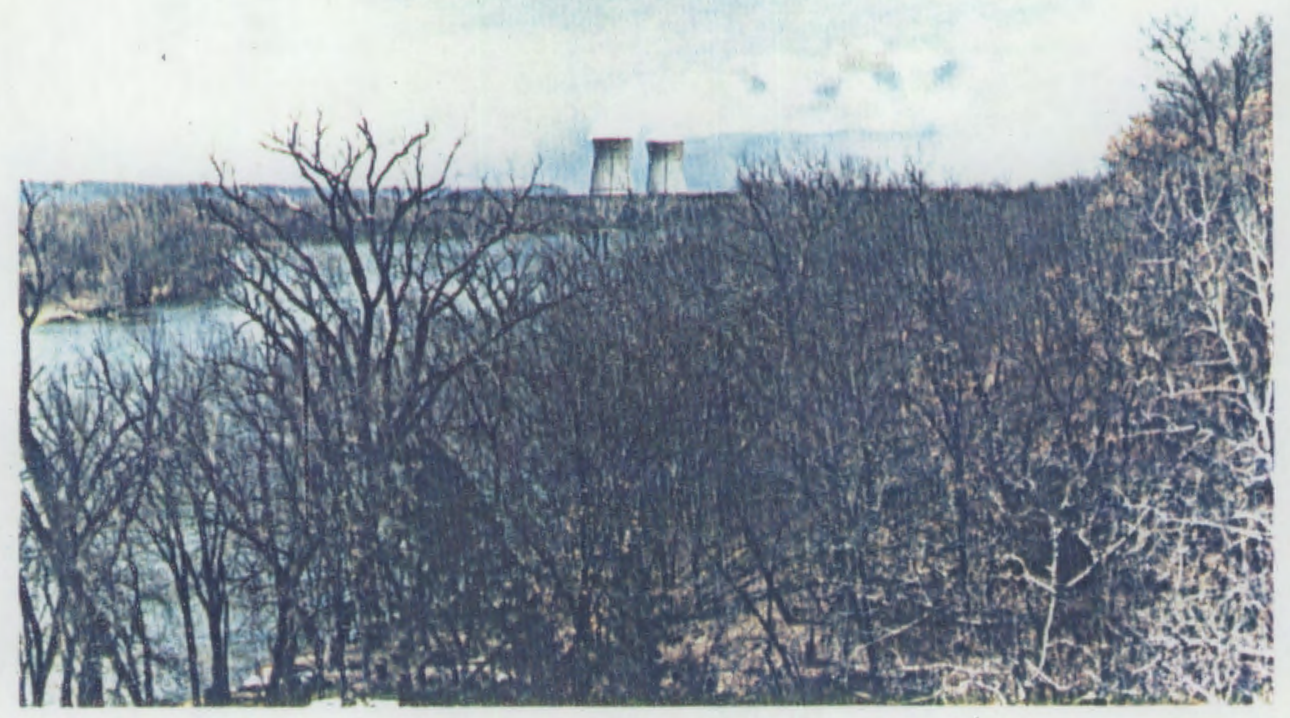

FIGURE 3. Application Photograph Example

The mean scores and standard deviations $\left(g_{j}\right.$ and $\left.\sigma_{j}\right)$ for all 29 variables are shown in Table 11 and are always treated as constants by the analyst (i.e., they were derived from the total population of this experiment).

Table 12 shows the standardized variable scores, $s_{j}$, for all 29 variables. These were calculated using Equation (6) and Table 11. For example, to calculate $s_{j}$ for variable 1 (i.e., $s_{1}$ ), Table 11 gives the mean score of variable $1, g_{1}$, as 4.70 and the standard deviation of variable $1, \sigma_{1}$, as 11.61 . From Table 10, the variable score for variable $1, g_{1}$, of the application photograph is 0 . Therefore, from Equation 6, the standardized variable score, $s_{1}$, for variable 1 in the photograph is:

$$
s_{1}=\frac{0-4.70}{11.61}=-0.405
$$

Step 3 requires the standardized variable score matrix $(S)$ to be multiplied by the factor score coefficient matrix $(H)$. This entails multiplying a $10 \times 29$ matrix by a $29 \times 1$ matrix. The result is a $10 \times 1$ matrix, F, termed 

TABLE 9. Variable Scores from Application Photograph

Variable

Score

(1) Percent of scene in clear, still water

(2) Percent of scene in clear, flowing water

(3) Slope of the steepest part of the river

(4) Slope of the flattest part of the river

(5) Percent of scene in white-water rapids

(6) Number of peaks in background

(7) Number of peaks in foreground

(8) Percent of scene in open field (no trees or crops) 0

(9) Slope of steepest bank to water 30

(10) Slope of flattest bark to water 0

(11) Percent of scene in cropland 0

(12) Percent of scene in trees in sumer foliage 0

(13) Percent of scene in trees (totai) 60

(14) Number of types of trees 4

(15) Percent of scene in residential buildings 0

(16) Percent of scene in power transmission facilities 0

(17) Percent of scene in manmade objects of stone or 0 brick (not residential structures, roads, or garbage)

(18) Percent of scene in other manmade structures (not 2 residential structures, roads, or garbage)

(19) Percent of scene in industrial parks or plants ?

(20) Percent of scene in manmade objects (not roads) 2

(21) Percent of scene in paved roads 0

(22) Percent of scene in gravel roads 0

(23) Percent of scene in garbage and debris from man 0

(24) Percent of scene altered by human activity 2

(25) Number of components in the scene $(a)$ B

(26) Number of distinct colors in the screen(a) 7

(27) Slope of steepest part of foreground 0

(28) Slope of steepest part of background 30

(29) Percent of scene in recreational areas $(b)$

(a) For further explanation of these variables, see Table 1.

(b) Note that, for one or two of the variables, there may be a slight variance in the variable score (for example, variable 29). That is, individuals might not arrive at exactly the same measure. These s?ight variations will not lead to significant changes in the final measure of aesthetic appeal. 
TABLE 10. Vector $(G)$ of Variabie Scores From Application Photograph

\begin{tabular}{|c|c|}
\hline Variable $(j)$ & $\begin{array}{c}\text { Variable } \\
\text { Scores }\left(g_{j}\right)\end{array}$ \\
\hline 1 & 0 \\
\hline 2 & 16 \\
\hline 3 & 0 \\
\hline 4 & 0 \\
\hline 5 & 0 \\
\hline 6 & 0 \\
\hline 7 & 0 \\
\hline 8 & 0 \\
\hline 9 & 30 \\
\hline 10 & 0 \\
\hline 11 & 0 \\
\hline 12 & 0 \\
\hline 13 & 60 \\
\hline 14 & 4 \\
\hline 15 & 0 \\
\hline 16 & 0 \\
\hline 17 & 0 \\
\hline 18 & 2 \\
\hline 19 & 2 \\
\hline 20 & 2 \\
\hline 21 & 0 \\
\hline 22 & 0 \\
\hline 23 & 0 \\
\hline 24 & 2 \\
\hline 25 & 8 \\
\hline 26 & 7 \\
\hline 27 & 0 \\
\hline 28 & 30 \\
\hline 29 & 0 \\
\hline
\end{tabular}


TABLE 11. Mean Scores and Standard Deviations

\begin{tabular}{|c|c|c|}
\hline Variable & $\bar{g}_{j}$ & $\sigma_{j}$ \\
\hline 1 & 4.70 & 11.61 \\
\hline 2 & 1.99 & 6.97 \\
\hline 3 & 4.25 & 18.03 \\
\hline 4 & 0.13 & 0.79 \\
\hline 5 & 0.80 & 3.99 \\
\hline 6 & 0.40 & 0.96 \\
\hline 7 & 0.03 & 0.16 \\
\hline 8 & 25.70 & 22.81 \\
\hline$g$ & 12.73 & 26.09 \\
\hline 10 & 3.43 & 11.89 \\
\hline 11 & 0.20 & 1.11 \\
\hline 12 & 10.75 & 16.00 \\
\hline 13 & 14.78 & 17.03 \\
\hline 14 & 1.68 & 1.42 \\
\hline 15 & 0.83 & 2.92 \\
\hline 16 & 3.00 & 5.52 \\
\hline 17 & 0.98 & 4.23 \\
\hline 18 & 7.62 & 14.33 \\
\hline 19 & 6.34 & 10.84 \\
\hline 20 & 9.48 & 12.82 \\
\hline 21 & 2.21 & 6.36 \\
\hline 22 & 1.86 & 6.18 \\
\hline 23 & 1.76 & 7.58 \\
\hline 24 & 25.02 & 26.55 \\
\hline 25 & 7.40 & 1.66 \\
\hline 26 & 6.70 & 2.17 \\
\hline 27 & 18.05 & 26.81 \\
\hline 28 & 38.23 & 33.40 \\
\hline 29 & 1.87 & 8.30 \\
\hline
\end{tabular}


TABLE 12. Standardized Variable Scores

\section{Variable (j)}

1

2

3

4

5

6

7

8

9

10

11

12

13

14

15

16

17

18

19

20

21

22

23

24

25

26

27

28

29
Standardized Variable Scores $\left(s_{j}\right)$

0.405

2.101

$-0.236$

$-0.165$

$-0.201$

$-0.417$

$-0.188$

$-1.127$

0.662

$-0.289$

0.180

$-0.672$

2.655

1.634

$-0.284$

$-0.544$

$-0.232$

$-0.392$

$-0.400$

$-0.584$

0.348

$-0.301$

$-0.232$

$-0.867$

0.361

0.138

$-0.673$

$-0.246$

$-0.225$ 
the factor score matrix. (a) For the photograph in Figure 3 , the results of multiplying the S matrix (Table 12) by the $\mathrm{H}$ matrix (Table 13) are shown as the $F$ matrix in Table 14 .

Once the $F$ matrix of factor scores is determined, the fourth and final step is to remove these scores $\left(f_{j}\right)$ from Table 14 and insert them into Equation (1) [see Table 4 for Equation (1) coefficients] to compute MLCAS for 1 andscape $i$ :

$$
\bar{Y}_{i}=\beta_{1}+\beta_{2} f_{i, 1}+\ldots+\beta_{11} f_{i, 10}+e_{i}
$$

This results in:

$$
\begin{aligned}
\hat{\bar{Y}}_{i}= & 27.407+4.368(-0.255)+3.186(0.854)-6.354(-0.592) \\
& 0.570(-0.221)-1.270(-0.468)+5.138(0.847)-4.447(0.598) \\
& 2.539(-0.219)-2.531(-0.461)+1.247(0.469) \\
\hat{Y}_{i}= & 36.137 .
\end{aligned}
$$

This means that the predicted MLCAS for the photograph shown in Figure 3 is equal to 36.137 on a scale from 0 to 50 .

Predicted MLCAS in conjunction with information on group socio-economic characteristics (including sex, education and nuclear attitudes) and the coefficients provided in Tables 6 and 7 can be used to predict a group VAS for a nuclear power $p l$ ant landscape. (b) A predicted group VAS will differ from the predicted MLCAS in two ways: 1) group VAS will reflect group socio-economic characteristics, and 2) the MLCAS aesthetic scale was different from the VAS aesthetic scale. This method of predicting group VAS then may, of course, be used to calculate visual aesthetic change; the difference between group VASs for two nuclear power plant landscapes.

(a) Matrix multiplication is briefly described in Appendix A.

(b) A detailed discussion of this procedure is provided in Reference 11. 
TABLE 13. Factor Score Coefficients

\begin{tabular}{|c|c|c|c|c|c|c|c|c|c|c|c|}
\hline & & actor 1 & Factor 2 & Factor 3 & Factor 4 & actor $\underline{5}$ & Factor 6 & Factor? & Factor $\underline{B}$ & Factor 9 & Factor 10 \\
\hline Variable & 1 & 0.00749 & -0.02748 & 0.00438 & -0.00938 & 0.01424 & 0.01276 & -0.00763 & 0.46940 & 0.14180 & 0.01528 \\
\hline ariable & 2 & -0.09203 & 0.39497 & 0.02772 & -0.00801 & 2601 & -0.07868 & -0.03735 & -0.03873 & 3168 & 4102 \\
\hline Variable & 3 & 0.18677 & 351 & 339 & 1 & 137 & 417 & 307 & 0315 & 483 & 5939 \\
\hline Variable & 4 & 0.33323 & -0.16587 & 0.05643 & 0.04408 & -0.03977 & 0.00320 & -0.01893 & 0.00956 & 0.08460 & 0.08841 \\
\hline ariable & 5 & -0.08732 & 0.39148 & .00871 & 0.02386 & 04214 & -0.08022 & 810 & -0.00767 & 4692 & -0.01151 \\
\hline Yariable & 6 & -0.02319 & -0.04590 & -0.14325 & -0.11057 & -0.10287 & -0.15754 & 0.13801 & 0.36282 & -0.12175 & -0.01953 \\
\hline Variable & 7 & 04103 & 0.01364 & 503 & & 460 & 438 & 594 & 0.02905 & 0.07720 & 8488 \\
\hline Variable & 8 & -0.08859 & -0.00240 & -0.00128 & -0.0 & 5673 & 463 & 1928 & -0.13977 & 0.16307 & 66995 \\
\hline ar iable & 9 & 54 & 0.12422 & -0.05469 & -0.04909 & -0.02904 & -0.08378 & 211 & 0.01370 & -0.05271 & -0.06664 \\
\hline ariable & & 0.28919 & -0.0 & & 260 & 3403 & -0. & $95 ?$ & -0.01034 & 647 & 0.02878 \\
\hline Variable & 11 & -0.03047 & 0.04227 & -0.03352 & -0.15303 & -0.15567 & -0.11102 & -0.11028 & -0.31762 & -0.05090 & 0.33064 \\
\hline ariable & 12 & -0.08608 & 0.10754 & -0.00017 & 0.00594 & 0.00534 & 0.25262 & 0.00570 & -0.00320 & 202 & 4832 \\
\hline Yariable 1 & & -0.03034 & 0.04836 & -0.11037 & -0.02540 & -0.01875 & 0.27416 & 1456 & 154 & -0. & 379 \\
\hline Variable 1 & 14 & 66 & -0.05681 & -0.0 & 05 & 1853 & 069 & 617 & -0.02713 & 266 & 0.19381 \\
\hline Variable & & 40 & & 847 & 71 & -0.00298 & -0.07299 & 760 & 0.05256 & 672 & 6614 \\
\hline Variable & 16 & -0.01951 & 05 & 0.30460 & -0.05368 & -0.08914 & -0.04151 & -0.03709 & -0.03218 & -0.11475 & 0.02564 \\
\hline $\operatorname{Var} i a b l e$ & & -0.006263 & 0.03795 & -0.0 & 0.00 & 0.49634 & 102 & -0 . & 175 & 31 & 1066 \\
\hline Variable & & -0.03683 & 0.03264 & -0.0 & -0.02722 & 0.40246 & 0.03884 & 783 & -0.03510 & -0.05354 & 0.00829 \\
\hline Variable & 19 & -0.03028 & 0.02635 & -0.04703 & 0.00607 & -0.03698 & -0.04815 & 263 & 0.02066 & 1047 & 0.08933 \\
\hline Variable & 20 & -0.03008 & 0.04969 & 0.09680 & -0.02504 & 0.03313 & 0.03477 & 0.19269 & -0.02995 & 0.08526 & 0.08035 \\
\hline Variable & 21 & 0.02115 & -0.00979 & -0.00674 & 0.46124 & -0.01157 & 0.08788 & 0.06171 & -0.04002 & -0.00426 & 0.00345 \\
\hline Variable & 22 & -0.06265 & -0.00155 & -0.00185 & -0.10535 & -0.04111 & -0.02888 & -0.06410 & 0.01670 & -0.09664 & -0.51004 \\
\hline Variable & 23 & & & 0.37273 & 0.00315 & -0.07517 & 0.08953 & -0.08387 & -0.02973 & -0.06747 & 0.07072 \\
\hline Variable & 24 & -0.00473 & -0.01059 & 0.20957 & 0.09919 & 0.08467 & 0.08720 & 0.08197 & 0.02458 & 0.02723 & -0.09076 \\
\hline Variable & 25 & 0.03541 & 0.01767 & 0.24888 & -0.01534 & 0.01703 & 0.00049 & -0.13613 & 0.18273 & -0.04343 & 0.38334 \\
\hline Variable: & 26 & -0.04392 & 0.09304 & 0.03038 & 0.16631 & 0.07674 & -0.10039 & -0.15092 & 0.21115 & -0.08866 & 0.14003 \\
\hline Variable & 27 & 0.18220 & -0.12192 & -0.11007 & -0.05414 & 0.19373 & 0.01724 & 0.05118 & -0.08046 & -0.23734 & 0.06342 \\
\hline Variable & & 0.10689 & 0.03788 & 0.19480 & -0.05530 & 0.07539 & & -0.22726 & 0.15617 & 0.21104 & -0.21220 \\
\hline Variable & 29 & 0.02185 & -0.11629 & 0.10462 & 0.02801 & 0.05795 & 0.39280 & 0.00213 & -0.04681 & -0.06163 & -0.12268 \\
\hline
\end{tabular}


TABLE 14. Factor Scores

\begin{tabular}{cc} 
Factor $(j)$ & Factor Score $\left(f_{j}\right)$ \\
\hline 1 & -0.255 \\
2 & 0.854 \\
3 & -0.592 \\
4 & -0.221 \\
5 & -0.468 \\
6 & 0.847 \\
7 & 0.598 \\
8 & -0.219 \\
9 & -0.461 \\
10 & 0.469
\end{tabular}




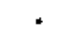




\section{REFERENCES}

1. G. P. Jones et al., Visual Impact Study: Statement of Findings, A7ternative Closed Cycle Cooling Systems, Indian Point Nuclear Generating PTant. U.5. Nuclear Regulatory Cormission, Washington, D.C., November 1975.

2. L. M. Arthur, "Predicting Scenic Beauty of Forest Environments: Some Empirical Tests." Forest Service. 23(2):1951-1959, June 1977.

3. R. D. Brush and E. L. Shafer, "Appljcation of a Landscape-Reference Mode 1 to Land Management," Landscape Assessment: Values, Perceptions and Resources. E. Zube, R. Brush, and J. Fabos, eds., Dawden, Hutchinson \& Ross, Inc., 1975.

4. T. C. Daniel, "Mapping the Sçenic Beauty of Forest Landscapes." Leisure Sciences. $7(1): 35-52,1977$.

5. G. L. Peterson and E. S. Newmann, "Modeling and Predicting Human Response to the Visual Recreation Environment." Journal of Leisure Research. $1(3): 69,1969$.

6. G. L. Peterson, "A Model of Preference: Quantitative Analysis of the Perception of the Visual Appearance of Residential Neighborhoods. "Journal of Regional Scjence. $7(1): 19-31,1967$.

7. M. J. Redding, "Aesthetics in Environmental Planning." Prepared for Office of Research and Development, U.S. Environmental Protection Agency, Washington, D.C., November 1973.

8. K. J. Lancaster, "A New Approach to Consumer Theory." Journal of Political Economy. 74:132-157, Apri1 1966.

9. G. C. Chow, "Tests of Equality Between Sets of Coefficients in Two Linear Regressions." Econometrica. 28(3):591-605, July 1960.

10. C. F. Christ, Econometric Models and Methods. John Wiley \& Sons, Inc., New York, N.Y., 1966.

11. R. C. Adams, J. W. Currie, J. A. Hebert and R. Shikiar, The Visual Impact of Alternative Closed Cycle Cooling Systems, Main Report. NUREG/CR-0989, PNL-2952, Pacific Northwest Laboratory, Richland, Washington, April 1980 . 
APPENDIX A

SOME BASIC CONCEPTS IN MATRIX ALGEBRA 
APPENDIX A

SOME BASIC CONCEPTS IN MATRIX ALGEBRA

In many situations, it is convenient to use symbols of the form

$$
\left[\begin{array}{cccc}
a_{11} & a_{12} & \cdots & a_{1 n} \\
a_{21} & a_{22} & \cdots & a_{2 n} \\
\cdots & a_{i j} & \vdots \\
a_{m 1} & a_{m 2} & \cdots & a_{m n}
\end{array}\right]
$$

in which each element, symbolized by $a_{i j}(i=1,2, \ldots, m j=1,2, \ldots, n)$, represents a number. Such a symbol is called a matrix, and each $a_{i j}$ is the entry of the matrix whose address is the pair $(i, j)$. Here "m" and " $n$ " may be any positive whole numbers, and the matrix is said to have dimension $m \times n$. For a fixed $i$, the symbol

$$
\left[\begin{array}{c}
a_{i 1} \\
a_{i 2} \\
\cdot \\
\cdot \\
\cdot \\
a_{i n}
\end{array}\right]
$$

is called the ith row of the above matrix. Similarly, for a fixed $j$, the symbol 


$$
\left[\begin{array}{c}
a_{1 j} \\
a_{2 j} \\
\cdot \\
\cdot \\
\cdot \\
a_{m j}
\end{array}\right]
$$

is the $j$ th column of the matrix. An $m \times n$ matrix has $m$ rows and $n$ columns. An $m \times 1$ matrix, which has just one column, may be called a column vector of dimension $m$. In this case, the subscript $j$ can only be 1 , and is regulariy omitted. Similarly, a $1 \times n$ matrix is called a row vector of dimension $n$ and the first subscript is normally omitted.

If $A$ is an $m \times n$ matrix and $B$ is an $n \times p$ matrix, the product $C=A B$ is the $m \times p$ matrix whose entry at address $(i, k)$ is the number obtained by multipiying the entries of the ith row of $A$ by corresponding entries of the kth column of $B$ and adding. More formally,

$$
c_{i k}=\sum_{j-1}^{N} a_{i j} b_{j k}=a_{i 1} b_{1 k}+a_{i 2} b_{2 k}+\ldots+a_{i n} b_{n k} .
$$

For example,

$$
\left[\begin{array}{rrr}
3 & -1 \\
0 & -2 & 2 \\
4 & 1 & 3
\end{array}\right]\left[\begin{array}{r}
1 \\
-1 \\
2
\end{array}\right]=\left[\begin{array}{llll}
3 & 1+0(-1)+1 & 2 \\
0 & 1+(-2)(-1)+2 & 2 \\
4 & 1+1(-1)+3 & 2
\end{array}\right]=\left[\begin{array}{l}
5 \\
6 \\
9
\end{array}\right]
$$

The product $A B$ is defined only when $A$ has exactly as many columns as $B$ has rows. 


\section{DISTRIBUTION}

No. of

Copies

OFFSITE
A. A. Churm
DOE Patent Division
9800 S. Cass Avenue
Argonne, IL 60439
2 DOE Technical Information Center

M. Kaltman

Regional Impact Anatysis Section

U.S. Nuclear Regulatory Commission

Lugenbee T Building

Room L-237

4922 Fairmont Avenue

Bethesda, MD 20115

D. Cleary

Regional Impact Analysis Section

U.S. Nuclear Regulatory Commission

Lugenbeel Building

4922 Fairmont Avenue

Bethesda, MD 20115
No, of

Copies

2 NRC Division of Technical

Information and Document Control

Washington, DC 20555

C. Prichard

Environmental Effects Branch

Division of Safeguards, Fuel

Cycle \& Environmenta1

Research

Mail Station 113D SS

U.S. Nuclear Regulatory Cormission

Washington, DC 20555

\section{ONSITE}

50 Pacific Northwest Laboratory

R. C. Adams (10)

J. W. Currie (33)

Publishing coordination (2)

Technical Information KE (5) 
